\title{
The Innovation of Disruptive Learning Media with Augmented Reality Based 3D Object Concept with Drill Machine Design to Improve Quality of Distance Learning in The Era of Education 4.0
}

\author{
$\underline{\text { https://doi.org/10.3991/ijim.v15i12.21579 }}$ \\ Andika Bagus Nur Rahma Putra $\left.{ }^{\bowtie}\right)$, Amat Mukhadis, \\ Nurul Ulfatin, Tuwoso, Mahfudi Sahly Subandi, Hardika \\ State University of Malang, Malang, Indonesia \\ andika.bagus. fteum.ac.id \\ Abd Kadir Muhammad \\ Tun Hussein Onn University Malaysia, Parit Raja, Malaysia
}

\begin{abstract}
Currently, the world of education is entering a disruptive era. Digital-based educational technology. Especially in the distance education model. The technology used is relatively unsophisticated. This study aims to: (1) develop Disruptive Innovation learning media with Augmented Reality with the concept of 3D objects in the form of a Drill Machine; (2) testing the attractiveness of Disruptive Innovation Learning media with Augmented Reality with a 3D Object Concept in the form of a Drill Machine; and (3) analyze the product's effectiveness. Research and development (R\&D) and quasiexperimental research are used as research methods. In this analysis, two expert teams validated the product, one for e-learning media and the other for vocational education materials. The results of the study found that augmented reality technology that focuses on $3 \mathrm{D}$ objects in the form of drilling machines has high effectiveness. Technology that is focused on augmented reality in the education 4.0 with $3 \mathrm{D}$ models in the form of a drilling machine will increase vocational school students' comprehension.
\end{abstract}

Keywords-Augmented Reality, 3D objects, distance learning, vocational education, education 4.0

\section{Background}

The generation of education has arrived. In all aspects of education, 4.0 is directly linked to digitization. Education 4.0 emphasizes the concept of learning, which focuses on direct student experimentation to find new things [1]. The role of digital technology is inextricably linked to the main aspect of education. Because of the increased access to information, the position of digital technology narrows the globe [2]. Changes in the use of digital media encourage education stakeholders to adjust. Ironi- 
cally, vocational education is still not completely prepared to deal with this transition. One of the flaws is that universities' current learning media facilities can't always keep up with technical advancements in the industry [3], [4].

The quality of distance learning in the world of vocational education is also not optimal in facing this challenge. In fact, this is contrary to the concept of distance learning, which focuses on learning design, interaction, participant motivation, and of course, the role and technology used [5]. Fulfilling the quality of distance education will have an impact on students' abilities, which is almost equivalent to learning in the class [6]. With the right approach and policies, the effectiveness of digital learning for students can be increased [7].

Educational media based on digital technology must be applied in all fields, especially vocational education. First and foremost, modern technologies should be developed in vocational education [8], [9]. The introduction of technology should have been carried out in educational institutions before plunging directly into the industrial world. However, vocational education institutions have not done so to their full potential. This will have an effect on the industry's low rate of vocational student graduates being absorbed. This technological development poses a challenge to prepare the competencies needed by the industrial world [10] - [13]. This challenge is the main focus that must be resolved by the role of educational institutions.

The ability of augmented reality technology to address problems and issues in the field of education is well recognized. AR technology transforms the physical world into a digital representation. The aim of AR technology is to show imagination in a realistic and detailed manner in both 2D and 3D. Students would be aware of the more precise specifications thanks to Augmented Reality. This knowledge is in line with the needs of companies interested in integrating AR into their processes [14]. Attractivity as with any technology integration process, Augmented Reality (AR) is determined to meet the need for good content, implementation, and assessment [15].

The study's aim was to develop virtual reality technology based on the concept of a 3D object in the form of a drilling machine in order to enhance the quality of distance learning for vocational students in the 4.0 education era. The aim of the project is to improve the standard of distance learning for vocational education institutions when it comes to transferring information to students.

\section{Method}

This research uses a research and development (R\&D) approach, which is supported by a quasi-experimental approach. This approach is oriented to the study's goals, which include the development of technology and the analysis of the product's effectiveness. Figure 1 depicts the entire product development process. 


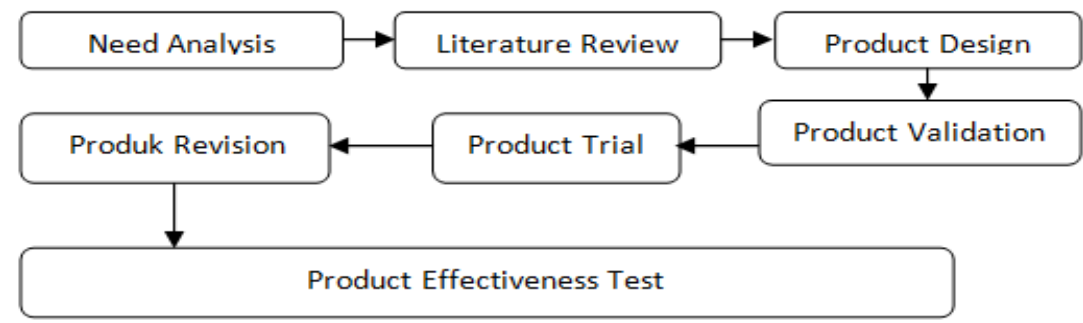

Fig. 1. Development Stages Scheme

Figure 1 shows that the research design used includes seven stages of research. Two specialist teams carried out the validation test. The team is made up of e-learning media experts and vocational content experts. Data collection using expert validation questionnaires. Analysis of research data using quantitative descriptive analysis techniques.

\section{Result}

The research findings are divided into three categories, namely: (1) The outcomes of a augmented reality technology implementation based on 3D objects in the form of drilling machines; (2) Experts in e-learning media and vocational education material have validated the findings; and (3) The findings of product effectiveness tests are one of the subjects that will be explored.

\subsection{The findings of the innovation of augmented reality}

This research can result in a $3 \mathrm{D}$ object-based augmented reality technology innovation in the type of a drilling machine. Figure 2 shows the display of the product application that is currently being created.

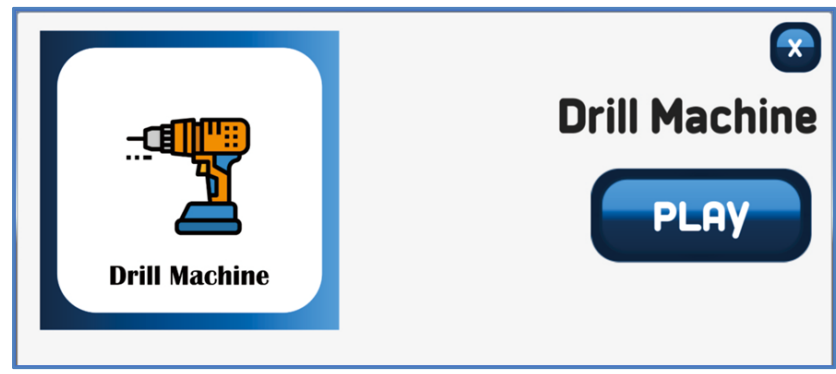

Fig. 2. Product homepage view 
Figure 2 depicts the product's home page, which contains several complex components. A marker picture, program name, 'play' button, and 'close' button are among the components. In addition, Figure 3 depicts the AR view if the 'play' button is pressed.

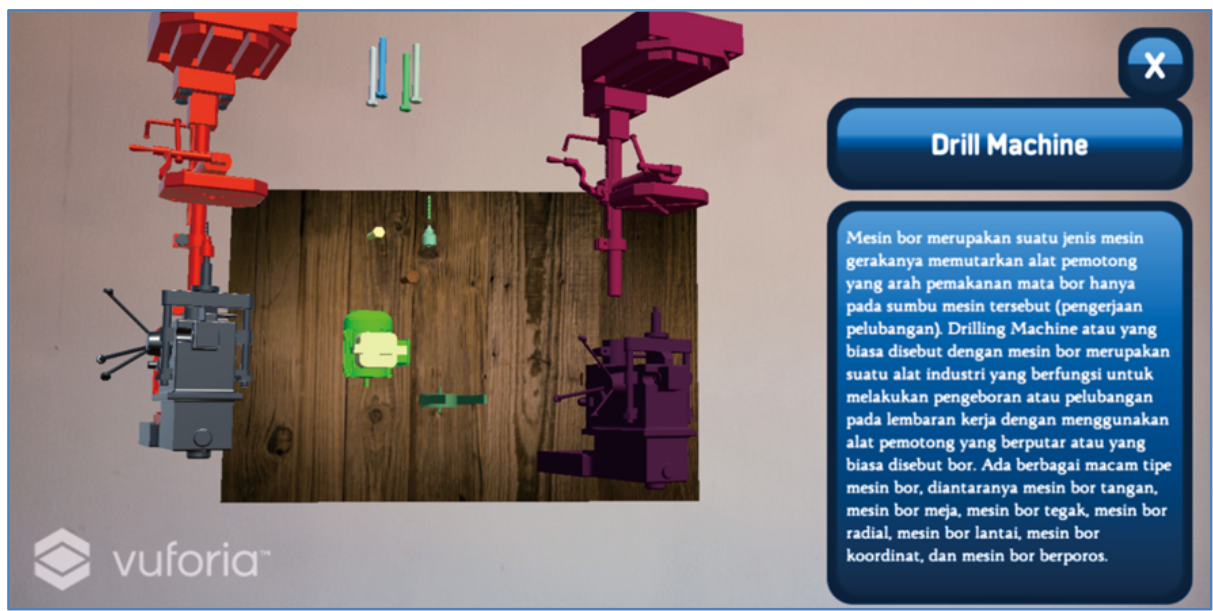

Fig. 3. AR 'play' display

In camera mode, the AR application is shown in Figure 3. The size of the AR screen is divided into three sections. The first component is a 3D object in the shape of a drilling machine. This section includes the whole object and the object of each component. The second part is a description of the object. Contains specifications and a brief description of the object. The third part is the 'close' button, which functions to exit camera mode.

\subsection{The results of the validation}

In this analysis, two teams of experts validated the results. The results of data processing from media expert validation include a number of components, which are detailed in Table 1.

Table 1. The results of the e-learning media expert's validation

\begin{tabular}{|c|l|c|c|}
\hline No. & \multicolumn{1}{|c|}{ Indicator Items } & Score & $\%$ \\
\hline 1 & The suitability of the display & 4.00 & 100.00 \\
\hline 2 & The attractiveness of the parent material & 3.50 & 87.50 \\
\hline 3 & Users' ability to read material with ease & 3.33 & 83.33 \\
\hline 4 & Colors, icons, and menus should all be in harmony & 4.00 & 100.00 \\
\hline 5 & Easy understanding & 4.00 & 100.00 \\
\hline
\end{tabular}

There are five key components in Table 1. Experts in instructional media have confirmed this. The score obtained for indicator items one, four, and five is 4.00. (100 percent). The learning media produced are of high quality and have a high viability. Table 2 also shows the processed validation by a group of vocational content experts. 
Table 2. Vocational material expert validation results

\begin{tabular}{|c|l|c|c|}
\hline No. & \multicolumn{1}{|c|}{ Indicator Items } & Score & \% \\
\hline 1 & The suitability with the target competency targets & 4.00 & 100.00 \\
\hline 2 & The amount of information presented & 3.33 & 83.33 \\
\hline 3 & The complete presentation of images and videos & 4.00 & 100.00 \\
\hline 4 & The degree at which legitimate references can be found & 4.00 & 100.00 \\
\hline 5 & The suitability of the performance indicators on the variable bill & 3.80 & 95.00 \\
\hline
\end{tabular}

There are five components in Table 2. The score obtained is 4.00 on the first, second, and fourth indicator points (100 percent). It can be assumed that the produced vocational content is of high quality and has a high degree of viability.

\subsection{Product effectiveness test results}

The effectiveness of a product is tested by experimental research. At this point, there were two groups: the control group and the experimental group. The first stage of the study was used to assess the initial skills of the two groups. Table 3 displays the learning outcomes of students' learning abilities prior to treatment.

Table 3. T-test results of initial ability test before treatment

\begin{tabular}{|c|c|c|c|c|}
\hline \multicolumn{5}{|c|}{ T-test for Equality of Means } \\
\hline $\boldsymbol{T}$ & $\boldsymbol{D} \boldsymbol{f}$ & Sig. & Mean Difference & Std. Error Difference \\
\hline-1.11 & 56 & .28 & $-1,84$ & 1.68 \\
-1.11 & 54,356 & .28 & $-1,84$ & 1.67 \\
\hline
\end{tabular}

Table 3 shows that student learning outcomes before being given treatment. The significance value for these findings is 0.275 , according to the description. This suggests that there is no substantial difference between the two classes' initial skills. The results of the final skill test are shown in Table 4.

Table 4. T-test of the Final Ability Test After being given the treatment

\begin{tabular}{|c|c|c|c|c|}
\hline \multicolumn{4}{|c|}{ T-test for Equality of Means } \\
\hline $\boldsymbol{T}$ & $\boldsymbol{D f}$ & Sig. & Mean Difference & Std. Error Difference \\
\hline 7,6 & 56 & .004 & 11.9852 & 1.5798 \\
7,6 & 53,167 & .004 & 11.9852 & 1.5758 \\
\hline
\end{tabular}

Table 4 shows the student learning outcomes after receiving treatment. The significant value is 0.04 based on these findings (sig. 0.04). This demonstrates that the final skill test results of the two groups vary significantly. It is possible to conclude that the established $3 \mathrm{D}$ object product is very accurate. 


\section{Discussion}

This session's discussion was split into two parts. The development of augmented reality technology as an e-learning medium is one of these subjects. Then, to increase the standard of distance education for vocational students, AR technology will be used.

\subsection{AR Technology development}

The AR technology developed in this study is one of the digital technology-based learning media. The validation results show that each of the three measures of elearning media growth receives a perfect score. In addition, there are three key measures in the results of the validation of vocational content that have a high acceptance rating, namely a percentage score of $100 \%$.

Student learning experiences are related to the role of online learning technology so that if the quality of learning technology is good, the quality of student learning experiences will be good [16]. According to some sources, in order to be creative with eLearning technology, the advantage of digital learning media used must be able to replicate real learning media, particularly in vocational education [17]. In this technology, the suitability of the media display being developed is presented in detail on each AR page. Also, this technology development also takes into account the attractiveness of the design and ease of use.

In essence, this AR technology learning media acts as a means to achieve learning goals. Learning objectives exist to provide a focused mindset for students involved in the use of learning content, while the world of education views learning objectives as administrative requirements that have little impact on teaching or student performance [19]. The use of learning media following the target competency targets must have relevance. Learning media has the primary function of increasing the effectiveness of student learning [20]. This is unquestionably in line with the technology's key goal, which is to improve the standard of distance learning for technical education. The findings of the study on learning technology reveal that technology serves six primary functions. The role of this technology can enhance students' learning experiences in visual and auditory forms. The visual form consists of visual effects, images, animation, and functions that focus students on important things and present concrete things, process complex information and increase student participation. The form of the hearing consists of background music and sound effects to arouse students' motivation and a learning experience [21], [22].

\subsection{The effectiveness of AR technology}

The improvement in the quality of distance learning for vocational students is one of the two key functions of developing AR learning media. AR learning environment can improve learning outcomes [23], [24]. AR learning media changes the focus of learning that leads to student-centeredness. Improving the standard of students' digital 
literacy will help to improve the quality of their learning. AR learning media allows students to develop digital literacy skills, which will have an impact on learning outcomes [21]. This technology makes it easier for lecturers to solve problems with students' learning. Furthermore, lecturers can reflect, engage in conversation with students, and provide individualized assistance [25]. AR media can be said to be an innovative learning media [26].

\section{Conclusion}

The findings are divided into several parts. This drilling machine has a high validity because it was created using virtual reality technology and 3D models. The drill machine-based object-based 3D augmented reality technology that was developed has been shown to improve vocational students' comprehension skills in the classroom. The findings of this article's research and development can be seen as a starting point for creating more advanced learning technologies with a broader scope.

\section{Acknowledgement}

Thank you to Universitas Negeri Malang (UM), which has enthusiastically funded this research under the PNBP UM 2020 and DRPM 2020 schemes.

\section{$7 \quad$ References}

[1] F. Almeida and J. Simoes. (2019). The role of serious games, gamification and industry 4.0 tools in the education 4.0 paradigm. Contemp. Educ. Technol. https://doi.org/10.30935/ cet.554469

[2] K. Umachandran et al (2019). Designing learning-skills towards industry 4.0. World J. Educ. Technol. Curr. Issues.

[3] T. Philbeck and N. Davis. (2019). The Fourth Industrial Revolution: Shaping A New Era. J. Int. Aff., vol. 72, no. 1, pp. 17-22.

[4] [A. Malik. (2019). Creating Competitive Advantage through Source Basic Capital Strategic Humanity in the Industrial Age 4. 0. Int. Res. J. Adv. Eng. Sci.

[5] A. Valai, DA Schmidt-Crawford, and KJ Moore. (2019). Quality Indicators for Distance Learning: A Literature Review in Learners' Perceptions of Quality. Int. J. E-Learning.

[6] R. Fojtík.Problems of Distance Education. Int. J. Inf. Commun. Technol. Educ., 2018.

[7] Di Xu and Ying Xu. (2019). The Promises and Limits of Online Higher Education- Understanding How Distance Education Affects Access, Coast, and Quality. Am. Enterp. Inst.

[8] ABNR Putra, A. Mukhadis, EE Poerwanto, W. Irdianto, and AI Sembiring. (2018). LMS Technology by Using Makerspace Approach on Unique Experiments-Based through MOOCs in Improving the Professional Competence of Vocational Students Paper. in 3rd International Conference on Sustainable Information Engineering and Technology, SIET 2018 - Proceedings. https://doi.org/10.1109/siet.2018.8693194

[9] W. Irdianto and ABNR Putra. (2016). The Influence of Education and Economic Background Towards the Training Participants' Motivation and Study Result of UPT-PK Singo- 
sari Malang. in AIP Conference Proceeding, vol. 1778, pp. 1-7. https://doi.org/10.1063 11.4965795

[10] G. Büchi, M. Cugno, and R. (2020). Castagnoli.Smart factory performance and Industry 4.0. Technol. Forecast. Soc. Change.

[11] M. Ghobakhloo. (2020). Industry 4.0, digitization, and opportunities for sustainability. Journal of Cleaner Production.

[12] E. Rauch, C. Linder, and P. Dallasega. (2020). Anthropocentric perspective of production before and within Industry 4.0. Comput. Ind. Eng. https://doi.org/10.1016/j.cie.2019.01 .018

[13] E. Pessl, SR Sorko, and B. Mayer. (2020). Roadmap industry 4.0 - Implementation guideline for enterprises. in 26th International Association for Management of Technology Conference, IAMOT 2017.

[14] LF de Souza Cardoso, FCMQ Mariano, and ER Zorzal. (2020). A survey of industrial augmented reality. Comput. Ind. Eng.,

[15] B. Baran, E. Yecan, B. Kaptan, and O. Paşayiğit. (2020). Using augmented reality to teach fifth grade students about electrical circuits. Educ. Inf. Technol., https://doi.org/10. 1007/s10639-019-10001-9

[16] RA Ellis and AM Bliuc. (2019). Exploring new elements of the student approaches to learning framework: The role of online learning technologies in student learning. Act. Learn. High. Educ., https://doi.org/10.1177/1469787417721384

[17] Muchlas. (2018). Developing an Online Learning Media Using Smartphones for the Electrical Machinery Course. Turkish Online J. Educ. Technol. - TOJET.

[18] J. Kerr and G. Lawson. (2020). Augmented Reality in Design Education: Landscape Architecture Studies as AR Experience. Int. J. Art Des. Educ. https://doi.org/10.1111/ jade. 12227

[19] KMW Mitchell and WR Manzo. (2018). The Purpose and Perception of Learning Objectives. J. Polit. Sci. Educ.

[20] A. Mukhadis, ABNR Putra, AM Nidhom, A. Dardiri, and H. Suswanto. 92018). The Relevance of Vocational High School Program with Regional Potency Priority in Indonesia. J. Phys. Conf. Ser., vol. 1028, pp. 1-8. https://doi.org/10.1088/1742-6596/1028/1/012079

[21] HP Hsu, Z. Wenting, and JE Hughes. (2019). Developing Elementary Students' Digital Literacy Through Augmented Reality Creation: Insights from a Longitudinal Analysis of Questionnaires, Interviews, and Projects. J. Educ. Comput. Res. https://doi.org/10.117 $\underline{7 / 0735633118794515}$

[22] HC Yeh and SS Tseng. (2020). Enhancing multimodal literacy using augmented reality. Lang. Learn. Technol.

[23] G. Papanastasiou, A. Drigas, C. Skianis, M. Lytras, and E. Papanastasiou. (2019). Virtual and augmented reality effects on K-12, higher and tertiary education students' twenty-first century skills. Virtual Real. https://doi.org/10.1007/s10055-018-0363-2

[24] YC Chien, YN Su, TT Wu, and YM Huang. (2019). Enhancing students' botanical learning by using augmented reality. Univers. Access Inf. Soc., https://doi.org/10.1007/s10209-0170590-4

[25] M. Heidarinejad, DA Dalgo, NW Mattise, and J. Srebric. (2018). Personalized cooling as an energy efficiency technology for city energy footprint reduction.J. Clean. Prod., https://doi.org/10.1016/j.jclepro.2017.10.008

[26] A. Macauda. (2019). Augmented reality environments for teaching innovation. Res. Educ. Media. 


\section{Authors}

Andika Bagus Nur Rahma Putra is a lecturer at Universitas Negeri Malang's Faculty of Engineering. Her research focuses on the use of technology in vocational education. His work has appeared in a number of journals and conference proceedings. He owns over 70 copyrighted learning software programs and actively contributes to the advancement of technology-based vocational education.

Amat Mukhadis Amat Mukhadis is a Professor at Universitas Negeri Malang's Faculty of Engineering. Her primary research interests include educational reform, quality assurance in education, and vocational education. Her research paper has been published in peer-reviewed journals, and she has given presentations at national and international conferences.

Nurul Ulfatin is a professor, Faculty of Education, Universitas Negeri Malang, Indonesia. Her research focus is on the field of education. She is active in many scientific activities as a resource. She is also a reviewer of national and international journals. She has published many books related to curriculum, online learning media, and education policy.

Tuwoso is an associate professor, Faculty of Education, Ma-lang State University, Indonesia. Research that has been carried out is all in the field of vocational education. He has produced many scientific works and books with a focus on vocational education. He is also active in carrying out community service programs at the national and international levels.

Mahfudi Sahly Subandi is a writer who is active in vocational education. There are many online applications and programs as a learning medium that he has developed. He created the MOOC system as an interactive learning medium.

Hardika is an associate professor, Faculty of Education, State University of Malang, Indonesia. he is actively writing and researching related to social education. He has many published books, as well as articles published in reputable international journals. Currently he is the vice chairman of an educational institution (LP3) which is engaged in the development of lecturer pedagogic competencies.

Article submitted 2021-01-28. Resubmitted 2021-03-02. Final acceptance 2021-03-03. Final version published as submitted by the authors. 